\title{
Le brigand caché derrière les tréteaux de la révolution. Traductions et trahisons d'auteurs
}

\section{Philippe Bourdin}

\section{(2) OpenEdition \\ 1 Journals}

\section{Édition électronique}

URL : https://journals.openedition.org/ahrf/12020

DOI : 10.4000/ahrf.12020

ISSN : 1952-403X

Éditeur :

Armand Colin, Société des études robespierristes

\section{Édition imprimée}

Date de publication : 1 juin 2011

Pagination : 51-84

ISSN : 0003-4436

\section{Référence électronique}

Philippe Bourdin, «Le brigand caché derrière les tréteaux de la révolution. Traductions et trahisons d'auteurs », Annales historiques de la Révolution française [En ligne], 364 | avril-juin 2011, mis en ligne le 01 juin 2014, consulté le 24 avril 2022. URL : http://journals.openedition.org/ahrf/12020 ; DOI : https:// doi.org/10.4000/ahrf.12020 


\title{
LE BRIGAND CACHÉ DERRIÈRE LES TRÉTEAUX DE LA RÉVOLUTION. TRADUCTIONS ET TRAHISONS D'AUTEURS
}

\author{
Philippe BOURDIN
}

\begin{abstract}
La réputation des Brigands de Schiller passe vite les frontières, et le public français cultivé s'intéresse à la pièce l'année même de sa création (1782). Elle est bientôt traduite ou jouée en allemand à Strasbourg. Mais son succès en France est surtout dû à la transcription qu'en offre La Martelière sous le titre de Robert, chef de brigands. Version épurée et appauvrie de l'original, elle intègre cependant en 1792 une partie des attendus du théâtre patriotique, dans un contexte de guerre et de revendications économiques favorables au message libérateur et fraternel porté par l'émule de Robin des Bois. Le succès, vérifié dans les reprises par les théâtres provinciaux et d'amateurs, est tel que des suites sont envisagées, qui n'entraînent pas la même ferveur. Surtout, le terme de «brigand » subit de rapides évolutions sémantiques et relève désormais de l'injure politique, successivement adressée à l'adversaire royaliste puis à l'ennemi jacobin. Le théâtre porte trace de cette évolution, souvent au détriment de l'intrigue, avant que, répression politique et judiciaire aidant, sous l'Empire notamment, le personnage du brigand ne fasse plus recette.
\end{abstract}

Mots-clés : brigandage, théâtre patriotique, traduction, Vendée, jacobins, réaction thermidorienne.

Le public français est habitué, au travers des Almanachs qui ne cessent de les rappeler, de la chanson qui les colporte, aux aventures de Mandrin et de Cartouche. Dans le salon du duc d'Orléans, où brille Carmontelle, on ne dédaigne pas de s'amuser lorsque quelque vide-gousset paraît sur scène : le proverbe dramatique Les Deux filous, au titre explicite, campe 
ainsi les dénommés Vide-Poche et L'Hameçon, aux prises avec le marquis de Drouville. Mais dans ces habitudes et ces divertissements, on aurait bien du mal à distinguer autre chose que le reflet lointain d'une réalité sociale qui varie selon les ans et les provinces, qu'un habitus littéraire valorisant le brigand généreux. La dimension politique de cette figure repérée ne naît pas avec la Révolution. Les Brigands de Schiller deviennent une référence obligée d'un drame qui quitte les normes du baroque sans oser encore toutes les formes du romantisme; leur production et leur influence sur les jeunes générations allemandes prouvent aussi, si besoin était, les liens qui peuvent exister entre la représentation théâtrale et la révolte de rue. Leur adaptation en France dans les dernières années de l'Ancien Régime, puis leur représentation sous la Révolution, en ont d'autant plus d'écho. Elles procèdent cependant d'une nationalisation de l'œuvre, d'autant plus forte que les variations sémantiques autour du mot «brigand » sont nombreuses et ne cessent de s'enrichir de connotations politiques au cours de la décennie révolutionnaire, et particulièrement sous le Directoire, dont les serviteurs confondent volontiers sous l'accusation de brigandage les « anarchistes » et les « royalistes ». Il nous paraissait intéressant de voir comment ces mutations affectent ou non un théâtre de la Révolution en général prompt, surtout dans ses déclinaisons patriotiques, à saisir le mot et l'instant. Comment le moule matriciel de Schiller est-il retravaillé, voire refondu, abandonné, au gré des expériences politiques et sociales? Quelles contrefaçons suggère-t-il ${ }^{1}$ ? Les pièces de brigands ne finissent-elles pas par laisser s'échapper le terme même vers d'autres scènes, d'autres intrigues? Ne deviennent-elles pas un glacis essentiellement littéraire quand l'intérêt du spectateur militant demande un débat d'abord politique?

\section{Les Brigands de Schiller ou la matrice de toute ouvre}

Publiés en 1781 et créés sur scène à Mannheim l'année suivante, Les Brigands de Schiller sont très vite connus en France. La première critique française paraît dès 1782 dans la gazette Le Pot pourri, puis l'œuvre est jouée quatre fois en langue allemande à Strasbourg en 1785. Elle est

(1) Toutes les précisions qui suivent sur les salles et le nombre de représentations des pièces étudiées sont, sauf avis contraire, dues aux travaux d'André Tissier, Les spectacles à Paris pendant la Révolution. Répertoire analytique, chronologique et bibliographique, Genève, Droz, tome 1, 1992, p. 264 et 477; tome 2, 2002, p. 84, 94, 112, 155, 186-187, 216, 232, 259, 279, 398, 403, 438, 469 . 
traduite sous le titre Les voleurs dans le Nouveau théâtre allemand publié en douze volumes par Nicolas de Bonneville et Friedel à Paris, entre 1782 et 1785. De retour d'Allemagne en 1787, Louis-Sébastien Mercier dira sans détour dans le Journal de Paris son admiration pour cette dramaturgie neuve ${ }^{2}$. Mais la diffusion la plus réussie du drame viendra avec une adaptation, Robert, chef de brigands, par Jean-Henri La Martelière (Ferrette, 1761 - Paris, 1830), conseillé pour ce faire par Beaumarchais. Né en Haute-Alsace, et descendant d'une vieille famille allemande qui s'est notamment illustrée dans la magistrature, les Schwing den Hammer (littéralement : «brandis le marteau »), il a fait ses études outre-Rhin et a eu Schiller pour condisciple. Après un voyage initiatique en Europe, il s'est établi à Paris et a choisi de franciser son nom pour vivre de sa plume. Il restera toute sa vie fidèle à Schiller : non seulement il publie à Paris, dès 1789 , le théâtre complet de celui-ci, mais il adaptera une autre de ses pièces en 1824, sous le titre Fiesque et Doria, ou Gênes sauvée, une tragédie en cinq actes, qui vient clore une carrière de dramaturge marquée par quatre créations révolutionnaires, cinq autres sous le Consulat et l'Empire, des comédies, des drames ou des tragédies, des romans historiques (par exemple Alfred et Liska, ou le Hussard parvenu, en 1804; Le Cultivateur de Louisiane, en 1808) et des écrits de circonstance (ainsi la Conspiration de Bonaparte contre Louis XVIII, en 1815). Il est alors, à l'instar de beaucoup de ses confrères qui y trouvent les moyens de vivre de leur plume, installé dans l'administration centrale, en l'occurrence celle des droits réunis où il officie comme chef de bureau puis comme contrôleur extraordinaire ${ }^{3}$.

\section{L'argument du drame premier}

Le choix du premier drame de Schiller, publié à compte d'auteur en 1781, et emblématique du Sturm und Drang, ne doit pas seulement à l'amitié. Son succès outre-Rhin avait de quoi faire imaginer une suite

(2) Pierre Frantz, « Le crime devant le tribunal du théâtre : Les Brigands de Schiller et leur fortune sur la scène française ", Littératures classiques, $\mathrm{n}^{\circ} 67$ : « Réécritures du crime : l'acte sanglant sur la scène $\left(\mathrm{XVI}^{\mathrm{e}}-\mathrm{XVIII}{ }^{\mathrm{e}} \mathrm{s}\right.$.) », Paris, Honoré Champion, 2009, p. 219-230. Mercier écrit notamment : « La représentation, coupée en sept actes, dure quatre heures et ne paraît pas trop longue. Les scènes les plus pathétiques, les plus terribles, les plus tendres sont liées l'une à l'autre. Les applaudissements sont rares, mais le silence est attentif et profond. On est ému à chaque scène; car on assiste à une action qui approche de l'effrayante vérité ».

(3) Jean-Chrétien Ferdinand HoEfer, Nouvelle biographie générale, Firmin Didot, Paris, 1857, tome 29, p. 77-78. 
française. D'autant que les figures de Schiller, si elles doivent beaucoup à la Bible ou au poète Schubart (1739-1791), aux héros de fiction (Robin des Bois, le Roque Guichard de Cervantès, les rôles shakespeariens), sont aussi en phase avec la réalité sociale contemporaine et les " exploits » de Friedrich Schwan (1729-1760) ou de Cartouche (1693-1721), mentionné dans sa pièce - et aussi dans la critique du Pot pourri ${ }^{4}$. L'intrigue emprunte quelque peu à la lecture d'une autre pièce, Cartouche ou les Voleurs, de Marc-Antoine Legrand, et d'un « conte historique » de Diderot, Les deux amis de Bourbonne (1770), dans lequel deux frères de lait, Olivier et Félix ne cessent de s'entraider, de mêler leurs identités quasi gémellaires à la vie à la mort, amoureux, sans pour autant s'entredéchirer, d'une même fille. Pour laisser Olivier vivre sa passion, et aussi parce qu'il est " dégoûté de la vie », Félix se perd dans toutes sortes de métiers dangereux et marginaux, jusqu'à éprouver l'injustice du monde judiciaire. Schiller va donner une version noire, sans espoir, de cet hymne à l'amitié. Dans Die Raüber, Franz von Moor, être vil et sans scrupules, veut dépouiller Karl, son frère aîné et le brouiller avec leur père par le biais d'une lettre calomnieuse. Karl, le fils prodigue, qui espérait être pardonné, se révolte et devient chef d'une bande de brigands, constituée de camarades d'étude dévoyés, auxquels il est lié par un serment. Il désire punir une société corrompue et athée, personnifiée par son propre frère, et, reprochant à l'action divine son indifférence aux maux de la terre, trop lente, trop détournée, prétend s'y substituer. Se plaçant aux marges de la société, il ne recule pas devant le meurtre, la violence, comme si la fin justifiait les moyens. Plus tard, voulant revoir son père, qui le croit mort, il découvre que Franz l'a, entre autres traîtrises et monstruosités, enfermé dans un cachot. L'agnostique et brutal Franz, se moquant des croyances humaines et de la vie de ses vassaux, se suicide pour échapper à la vindicte fraternelle, pied de nez au ciel, ultime défi au monde et affirmation finale de sa liberté - non sans quelques frayeurs superstitieuses qui cependant n'entraînent nulle conversion, mais bien plutôt une réaffirmation plus radicale de ses convictions matérialistes : cette crise de conscience signe l'échec de sa philosophie puisqu'il est victime des mêmes angoisses, des mêmes contradictions que le reste de l'humanité. Le comte meurt de douleur en reconnaissant son fils Karl sous les traits d'un brigand. Karl veut quitter cette vie errante et sanguinaire et épouser Amalia, sa fiancée, unique figure féminine (et peut-être tragique) de l'intrigue, réfugiée dans

(4) Pierre Frantz, « Le crime devant le tribunal du théâtre ... », art. cit. 
le jardin, à l'écart des oppressants espaces du château (chambres, galeries, enfilades de pièces). Elle n'a cessé de l'aimer malgré la douleur silencieuse provoquée par l'absence du héros guerrier puis par l'aveu de ses forfaits, et a su résister aux pulsions de Franz. Mais ses compagnons rappellent Karl à son serment qui le lie indéfectiblement à eux : n'a-t-il pas juré de « faire de l'Allemagne une république », son second, Spiegelberg, entendant ressusciter les « héros allemands », tandis que les autres « libertins » de la bande, selon le mot de l'auteur, se complaisent dans des provocations anticléricales et sexuelles dignes de charivaris étudiants, avouant sans fard : « Sans Moor, nous ne sommes qu'un corps sans âme » (acte I, scène 2)? Déchiré entre ses obligations, Karl tue Amalia, qui l'a supplié de lui donner la mort, et se livre à la justice. Que ces thèmes puissent être transposés dans le domaine du politique ne fait aucun doute puisque la question de la légitimité du pouvoir et de la conspiration est clairement posée.

L'intrigue, conçue pendant les études de médecine de Schiller, n'est pas dissociable de ses observations sur les relations psychosomatiques, sur lesquelles il faisait alors un mémoire. C'est justement au nom de la vérité psychologique de ses personnages qu'il rejette l'académisme des unités et des genres pour assumer la bâtardise de son œuvre ${ }^{5}$, « une créature née de l'accouplement contre nature entre la subordination et le génie », " un monstre », dira-t-il lui-même - quoiqu'il continue de réserver aux coulisses les scènes de combat. Cette monstruosité tient aussi aux « êtres d'exception » dont il fait des protagonistes, réduisant leur vie entière à quelques heures. Elle marque Franz, ce cadet de famille conscient de son insignifiance, dont l'âme est aussi noire que le corps est difforme, génie malfaisant instrumentalisant chacun dans un rapport de pouvoir despotique, terroriste et paranoïaque, tombant en syncope au souvenir d'un cauchemar. Elle macule pareillement Karl, héros familial « doué de tous les dons pour atteindre l'excellence », mais victime d'une énergie débordante, des pulsions et des passions, et de son inféodation au groupe, d'une répudiation paternelle qui le convainc d'une haine universelle de laquelle le remède est le meurtre. Ce qui n'évite ni la dépression (la «mélancolie ») ni la régression infantile : une pulsion de fuite vers le château de son enfance qui, sitôt rejoint, devient comme la forêt une nouvelle prison où il mesure l'étendue de ses forfaits, ce qui fait que

(5) Sur ce concept de « bâtardise », voir Philippe Bourdin et Gérard Loubinoux (dir.), La scène bâtarde entre Lumières et romantisme, Clermont-Ferrand, Presses universitaires Blaise-Pascal, 2004. 
Karl n'aura de cesse de fuir les différents décors, qui font aussi partie de son paysage intérieur tourmenté 6 . La reconquête de sa liberté individuelle passe par la reconnaissance de sa responsabilité morale - et l'on sait combien, ultérieurement, Schiller admirera Kant -, mais aussi par la reconnaissance implicite d'un système politique qu'il dénonçait la veille.

\section{Désobéissance et autocensure}

Cette destruction de l'ordre social, ce combat contre la tyrannie, ce désespoir aussi marquent durablement la jeune génération allemande. Elle se reconnaît en Schiller qui, médecin militaire aux ordres du despotique duc de Wurtemberg, n'a pas hésité à contrevenir aux ordres en quittant son régiment pour assister à la première de sa pièce, le 13 janvier 1782, à Mannheim, subissant en retour quarante jours d'arrêt et décidant en septembre de la même année de fuir ses employeurs pour vivre de sa plume. Elle suit davantage encore Karl de Moor : dans quelques villes, les étudiants rêvent de se faire brigands pour réformer la société et, à Fribourg en Brisgau, se retrouvent dans les bois pour se transformer en anges exterminateurs. Ce faisant, ils oublient le profond pessimisme de leur héros (et de son démiurge), l'écœurement que provoquent en lui ses crimes, son désespoir et sa folie brutale qui lui font assassiner sa maîtresse, répudier son œuvre et ses complices ${ }^{7}$. Jusqu'au XIX ${ }^{\mathrm{e}}$ siècle, la chanson des Brigands demeure en tout cas emblématique d'un esprit de révolte, d'un désir de purification qui n'est pas incompatible avec le satanisme. Elle poursuit une tradition dont savait user Villon, et à laquelle se rattachera Orange mécanique :

(6) Pour ces citations de Schiller et les analyses qui suivent, cf. Georges Zaragoza, Gilles Darras, Christine MarCANDIER-Colard et Edgar SAMPER, Hérö̈sme et marginalité, Neuilly, Atlande, 2002 .

(7) George SAnd, Histoire de ma vie, in Euvres autobiographiques, Paris, PléiadeGallimard, 1970, p. 165-175 : «En poursuivant son œuvre de farouche rémunération, écrit Sand, Charles Moor s'aperçoit à chaque pas de son erreur fatale. Il ne lui est point possible de moraliser ses brigands philosophes et de rendre l'instrument digne de la cause. Pour punir un coupable, ils sacrifient cent victimes innocentes; pour frapper de leur poignard un cœur impur, il leur faut marcher sur des cadavres de femmes et d'enfants. Ces hommes ont pour eux certaines vertus particulières, une audace héroïque, un dévouement sans bornes les uns pour les autres, une loyauté chevaleresque dans leurs rapports avec leur chef; mais leurs passions aveugles ne peuvent se satisfaire que dans le meurtre et le pillage. Leurs pensées sont un cauchemar sanguinaire, leurs entretiens un blasphème désespéré ». 
« Voler, tuer, se battre, forniquer, Voilà ce qui s'appelle passer son temps!

Demain nous serons pendus au gibet,

Amusons-nous donc aujourd'hui.

Nous menons une vie libre,

Une vie de délices.

La forêt est notre quartier nocturne,

Sous le vent et l'orage nous campons,

La lune est notre soleil,

Et Mercure notre dieu

Qui connaît le métier.

Aujourd'hui nous nous convions chez les prêtres,

Demain chez le riche fermier;

Et quant au reste, n'ayons pas de souci,

C'est l'affaire du bon Dieu.

Et quand avec le jus de la grappe

Nous avons lavé notre gosier,

Nous avons de la force et du courage

Et nous formons un pacte fraternel avec l'esprit noir

Qui rôtit les âmes dans l'enfer.

Le gémissement des pères qu'on égorge,

Les lamentations des mères effrayées,

Les cris de la fiancée délaissée,

Sont notre bruit favori et notre joie.

Ah! Quand ils tremblent devant nous sous la hache,

Quand ils mugissent comme des veaux et tombent comme des mouches,

Notre œil étincelle,

Notre oreille est satisfaite.

Lorsque viendra notre dernière heure,

Le diable nous emporte!

Alors nous aurons notre récompense

Et nous graisserons nos bottes,

Sur la route un petit coup de vin généreux,

Et hourra! Hourra! Nous voilà partis! » 
Dans l'Histoire de ma vie, et précisant elle-même qu'elle rédige ces lignes en 1848, George Sand mesure l'influence de Schiller en Allemagne, en faisant l'égal de Voltaire et de Rousseau en France. Elle insiste tout aussitôt et sur les identités nationales peu conciliables ainsi déterminées, et sur la manière dont les œuvres échappent à leurs auteurs : «Le jeune Schiller révéla leur mal, la grandeur et la faiblesse de cette génération, qu'il peignit et agita dans le drame des Brigands avec tant de puissance et de naïveté. Cette révélation fut chez lui si spontanée qu'il ne s'en rendit pas compte et qu'il ne comprit point son œuvre », affirmant sa volonté d'édification morale tandis que le pouvoir la jugeait immorale et funeste ${ }^{8}$. Qu'elle fût jouée avait été une divine surprise, et le dramaturge avait pour ce faire accepté tous les changements réclamés par le baron de Dalberg, directeur du théâtre de Mannheim, ministre de l’Électeur palatin, celui-ci grand protecteur des lettres. La première édition, en mars 1781, prévoyait que l'action se déroulait pendant la guerre de Sept Ans. À l'automne, sous le titre un rien moqueur, et vite abandonné, Le fils prodigue ou les Brigands remaniés, elle est transportée au Moyen Âge, la profession de foi matérialiste de Franz, le récit des forfaits des brigands, sont raccourcis, privés pour les seconds des passages les plus crus. Les personnages du moine et du pasteur disparaissent. Franz ne se suicide plus mais est condamné à la prison perpétuelle, et son frère lui pardonne. Schiller avait vu les journaux polémiquer sur son texte, essuyé les protestations de la famille de Salis et du duc de Wurtemberg, outrés de voir en quelques répliques, succédanés d'un dicton populaire, détruite la réputation des Grisons ( « Il y a un génie national tout particulier, une espèce de climat, si je puis parler ainsi, propre à la friponnerie. Et, par exemple, va-t-en dans les Grisons, c'est là qu'est pour le moment la véritable Athènes de la filouterie ", dit l'un de ses personnages). Il avait fait amende honorable en supprimant la phrase de la deuxième édition. C'est du reste dans sa version expurgée que la pièce paraîtra en 1785 en France dans le Théâtre allemand. Selon le baron de Barante, l'un des traducteurs ultérieurs de son œuvre (en 1821), Schiller avait même pensé un temps réécrire Les Brigands, "mais, tout en se faisant des reproches, il disait que son ouvrage était comme ces jeunes mauvais sujets dont les qualités et les vices sont inséparables et forment un ensemble qu'on court le risque de gâter en cherchant à les corriger $»^{9}$.

(8) George SAND, op. cit.

(9) Prosper DE Barante, Études littéraires et historiques, Didier et C $\mathrm{C}^{\mathrm{ie}}$, Paris, 1859, p. $86-88$. 
Les retouches se limitèrent donc à l'intrigue du dernier acte. Toutefois, ces atermoiements et ces remords prouvent aussi combien aucun texte théâtral n'est alors considéré comme immuable, ce qui ouvre la porte à bien des adaptations ... C'est pourquoi paraissent quelque peu incongrus, déconnectés des préoccupations de Schiller, les reproches adressés à la traduction française de La Martelière par Germaine de Staël, qui joue pourtant un rôle majeur dans la connaissance en France de la littérature allemande : « On n'a pas tiré parti de l'époque qui donne un intérêt historique à cette pièce. La scène se passe dans le quinzième siècle, au moment où l'on publia dans l'Empire l'édit de paix perpétuelle, qui défendait tous les défis particuliers », ce qui entraîna les jeunes nobles à résister à cette « inertie honteuse » qu'on leur imposait, et excuse en partie Karl de Moor ${ }^{10}$.

\section{Robert, chef de brigands ou la captation d'héritage}

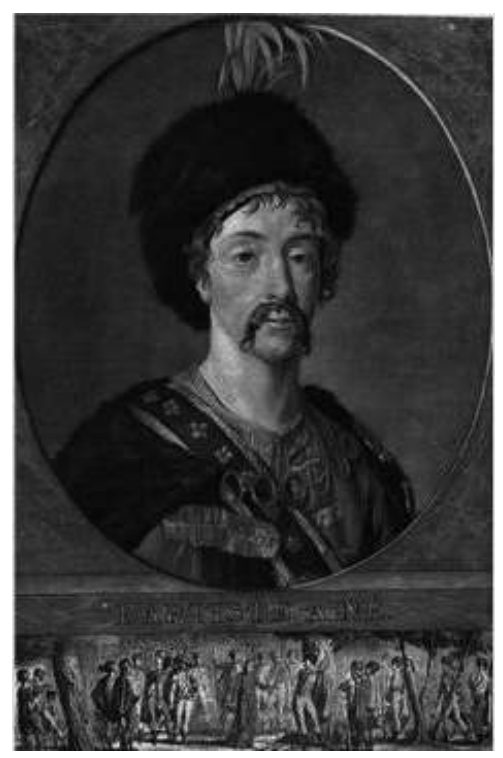

Baptiste aîné dans le rôle titre

(10) Germaine de StaËL, De l'Allemagne, Paris, 1810, chapitre XVII. 


\section{Une adaptation à succès}

Achevée dès 1786, en pleine crise parlementaire et sociale, et alors que la France va connaître elle aussi des mouvements d'étudiants, la transcription de La Martelière, un drame en cinq actes en prose comme l'original, ne sera jouée que le 10 mars 1792 au Théâtre du Marais. Le ministère Narbonne démissionne ce même jour en attendant que le roi, décidé à déclarer la guerre, en appelle aux girondins; la revendication d'une nécessaire taxation des grains a conduit au meurtre de Simoneau, maire d'Étampes, qui s'y opposait au nom du libéralisme (3 mars) : la guerre aux châteaux et aux tyrans, le désir d'unir le genre humain autour de valeurs communes, le sens du partage sont justement des moteurs de la pièce. Suivront 28 représentations cette même année et 17 en 1793 à partir du 30 mai, après une le 29 mai 1793 au Théâtre de la rue Feydeau par la troupe du Marais, enfin 30 en l'an II, à partir du 7 juin 1793, au Théâtre de la République. Au total, on compte au moins 160 représentations dans la capitale durant toute la décennie révolutionnaire ${ }^{11}$. On peut parler d'un véritable, d'un très important succès pour l'auteur. L'estime du public, et les moyens du quotidien ainsi procurés, lui permettent de publier Robert, chef de brigands, en 1793, chez Maradan et Barba, occasion aussi de répondre dans la préface à ses détracteurs, non sans quelque fausse pudeur et autant de clés pour confondre le brigand social (celui qui se nourrissait sur le peuple), et ne pas se tromper sur son apolitisme si nourricier qu'il admet la censure :

« On m'a reproché d'avoir mis des brigands sur la scène. Eh! Qu'importe le nom quand la chose n'y est pas? Plût au ciel que la société ne fût composée que de brigands semblables! Les loix seraient maintenues, les propriétés respectées, l'honnête homme y trouverait des amis, l'infortuné des secours; le méchant seul, sans appui, sans ressource, abandonné à lui-même, serait forcé de renoncer au crime, ou d'en porter la peine.

Quelques personnes ont cru voir du danger à présenter au public les principes d'une pareille morale : je suis loin de suspecter leur bonne-foi; et je déclare ici, avec toute la franchise dont je fais profession, que je n'ai point prétendu faire de cet ouvrage une pièce de circonstances.

(11) Emmet Kennedy, Marie-Laurence Netter et alii, Theatre, Opera and Audiences in Revolutionnary Paris. Analysis and Repertory, Wesport-Londres, Greenwood Publishing Group, 1996, p. 180. 
Étranger à toutes les sectes qui tour à tour ont figuré sur notre horison politique, je n'ai jamais connu d'opinion, de parti, que celui de la justice et des loix; mais le ministre déprédateur, le financier concussionnaire, le magistrat prévaricateur, le prêtre sacrilège et le prince oppresseur sont en tout tems, en tout pays, en politique comme en morale, des monstres aux yeux de tous les hommes. Eh bien! Voici les scélérats que je livre à l'indignation des honnêtes gens, et au tribunal de mes brigands. Si j'ai failli, il existe des magistrats pour veiller au maintien des bonnes mœurs, et des loix pour punir les corrupteurs de l'esprit public ».

Le succès est aussi vrai pour le Théâtre du Marais qui, fondé en 1660 et plusieurs fois déplacé jusqu'à sa fermeture en 1673, a retrouvé sa raison sociale en 1790 en s'installant rue Sainte-Catherine : son directeur, le citoyen Courcelles, doit même refuser des spectateurs tant Robert, proclamant fièrement «Guerre aux châteaux, paix aux chaumières! » attire les foules; des guichets fermés que la salle connaîtra à nouveau en juin 1792 avec La Mère coupable de Beaumarchais. Le succès, enfin, va aussi être celui d'un acteur, Baptiste aîné, qui reprend le rôle avec les « Rouges » du Français, et qui va à ce point 1'habiter que la postérité va saluer la performance d'un tableau en costume de scène. La Martelière lui-même, dans la préface à l'édition de 1793, n'omet point un éloge au comédien qui incarnait Robert :

«L'amitié et la reconnaissance me font un devoir de rendre ici hommage au talent du citoyen Baptiste. Cet acteur étonnant, et dont on peut à coup sûr prédire la haute célébrité, a mis dans son jeu tant de vérité et de profondeur, qu'il s'est en quelque façon approprié le succès de cet ouvrage. Cet éloge ne me serait pas échappé, si au talent d'un artiste consommé il ne joignait les qualités non moins rares, qui font estimer le citoyen $»$.

Fabien Pillet le contredira, qui éreintera Baptiste aîné dans sa Nouvelle lorgnette de spectacles, en l'an IX (p. 15-21) : amoureux incontestable de son art, imbattable en théorie, l'artiste laisse trop apparaître la méthode, accentuant syllabes, points et virgules, et de facto pédant et monotone; il fonde son jeu sur la seule expressivité, souvent outrée, de son visage, plus à l'aise dans la comédie que dans la tragédie; «son talent, qui est dans sa tête, seroit au-dessus de tous éloges s'il étoit placé dans son cœur »... Les historiens du théâtre de la première moitié du $\mathrm{XIX}^{\mathrm{e}}$ siècle pourtant, qui ont assisté à la prestation, la saluent encore pour la plupart, avec plus ou moins de nuances. Ainsi la Petite biographie dramatique, faite avec adresse par un moucheur de chandelle: 
«La retraite a vainement sonné, ce sociétaire a fait la sourde oreille. Le fameux Robert, chef de brigands, représenté par lui au théâtre de la rue Culture-Sainte-Catherine, il y a près de quarante ans, fut un des rôles où il excella, bien qu'il prêtât à son héros une taille de patagon, et qu'il le fît parler en capucin $\gg{ }^{12}$.

L'Histoire des petits théâtres de Paris, de Nicolas Brazier, fait faussement commencer la renommée de Baptiste à ce rôle : « La haute stature de ce comédien, sa figure sévère, sa diction grave, son maintien noble, le rendaient propre aux personnages qu'il était chargé de représenter ${ }^{13}$. Jules-Gabriel Guérin, dans son Histoire de la littérature dramatique, rappelant les autres interprétations de l'acteur, regrette que la violence du drame romantique n'ait pas encore été de mise, que les héritages de la gestuelle baroque brident encore le jeu et limitent les emplois, que le costume de scène joue sur l'implicite des contes de la bibliothèque bleue :

«Qui donc arrive? Quelle est cette voix qui sort de ce nez de mauvais augure, un pied de nez, autant que de cette bouche pincée en cœur? Malheureux, que dites-vous? C'est Baptiste aîné en personne, c'est le Philosophe sans le savoir, c'est le Métromane, c'est le Glorieux, c'est Robert, chef de brigands. [...] Robert, chef de brigands, était bon gentilhomme, comme Tartuffe; il portait des bottes molles et un habit neuf $»^{14}$.

Schiller est admiré par Marie-Joseph Chénier, le chantre (après Voltaire et avec Louis-Sébastien Mercier) d'un théâtre patriotique qui trouverait dans l'histoire le support de ses enseignements moraux, quoique depuis la prise de la Bastille, en passant par l'ouverture des couvents et la fuite du roi, ce soient davantage les événements contemporains qui nourrissent à partir de 1790 ce répertoire engagé. Les liens esthétiques et politiques du dramaturge allemand avec la France prennent en tout cas, notamment grâce à l'adaptation de La Martelière, une toute autre ampleur. La citoyenneté française lui est accordée le 6 septembre 1792, au lendemain des massacres. Le décret marque encore des hésitations sur l'identité du récipiendaire: selon la décision du conseil exécutif provisoire,

(12) Anonyme, Petite biographie dramatique, faite avec adresse par un moucheur de chandelle, Les Marchands de nouveautés (Imprimerie de Marchand du Breuil, rue de La Harpe, $n^{\circ} 80$ ), Paris, 1826.

(13) Nicolas Brazier, Histoire des petits théâtres de Paris, tome 1, Paris, Allardin, 1838, p. 11 .

(14) Jules-Gabriel Janin, Histoire de la littérature dramatique, Paris, Michel Lévy, 1855, tome 2, p. 239-240. 
signée par Clavière et Danton, "le sieur Gille, publiciste allemand», est accueilli au sein de la Nation française - Le Moniteur orthographiera «Gilleers $»^{15}$. Schiller aura lui-même l'occasion, dans les années suivantes, de transcrire des créations françaises : ainsi Médiocre et Rampant, de Louis-Benoît Picard (1797), devenu sous sa plume Le Parasite ou l'Art de faire sa fortune $(1803)^{16}$.

\section{Une intrigue retravaillée et appauvrie}

Robert, chef de brigands a de quoi séduire le public nombreux et averti, et use à dessein d'artifices politiques et scéniques. La scène d'exposition permet à l'héroïne, Sophie, amante de Robert de Moldar, chef de brigands, de repousser les avances du frère de celui-ci, Maurice, et de l'accuser d'avoir tourmenté les derniers moments de son père, jusqu'à lui faire répudier son aîné - le vieux comte, dont la mort a partout été annoncée, croupit en fait au fond d'un cachot. Maurice accuse Robert de débauches et de créances non honorées, parle d'une fuite volontaire et fait croire à Sophie qu'il la lui a abandonnée puis que Robert est mort, usant d'un intermédiaire déguisé en soldat, celui-ci fort apeuré du spectre du comte de Moldar ( Ces ossemens blanchis qui semblent se réunir, se ranimer \& s'élever de la nuit du tombeau contre la barbarie de ses assassins ", acte I, scène 5). Le stratagème évidemment échouera, et c'est Robert en personne, mais sous un pseudonyme, qui en avertira son aimée, avant d'être emprisonné par son frère (acte III, scènes 5 à 7) puis libéré par ses compagnons, tandis qu'une armée vient à leur rencontre (acte III, scènes 9 à 11). Cette intrigue amoureuse n'est toutefois que l'un des fils conducteurs de la pièce; un autre est tissé par les considérations politiques. Alors qu'elles enrichissaient le sujet de Schiller, La Martelière évince de son propos toutes les considérations psychologiques et poétiques, matérialistes ou religieuses - sinon quelques réflexions vite jetées sur l'Audelà (acte $\mathrm{V}$, scène 3 ) - : il fait de ses brigands des idéalistes porteurs de révolte, des étudiants allemands en France et des « patriotes de 1789 ».

Entre deux joutes sentimentales et familiales, est en effet arrivée la nouvelle qu'une troupe de brigands s'attaque aux châteaux, les pille, les brûle, exécute les propriétaires réputés iniques ou tyranniques - ce qui évi-

(15) Gerhard Schmid, Friedrich von Schiller, Bürger von Frankreich, Leipzig-Weimar, s.d.

(16) Philippe Bourdin, «Fustiger les parvenus : autour de Médiocre et Rampant, de Louis-Benoît Picard », dans Martial Poirson, Le théâtre sous la Révolution. Politique du répertoire (1789-1799), Paris, Desjonquères, 2008, p. 227-246. 
demment rappelle aux spectateurs, à l'époque où la pièce est jouée, ce que La Martelière ne pouvait prévoir, des épisodes récents de la Révolution de facto légitimés. Ainsi du comte de Marbourg, abandonné par ses courtisans réputés lâches, sur la poitrine duquel avait été épinglé ce papier infâmant, qui rappelle les écriteaux des piloris : "Arrêt de mort contre Adolphe, comte de Marbourg, pour cause d'oppression, par le tribunal criminel » (acte I, scène 7). Les méfaits qui lui sont reconnus rappellent les droits seigneuriaux, et celui de chasse notamment : «Sa mort peut-elle payer le sang des pères de famille qu'il fit périr dans ses prisons, pour avoir tué un cerf ou quelque autre gibier? Est-il de vexations qu'il n'ait commise, de propriété qu'il n'ait tenté d'envahir? Moi-même je l'ai vu, suivi de ses piqueurs \& de sa meute, dévaster de gaîté de cœur l'héritage du pauvre, \& l'écraser ensuite quand il osoit s'en plaindre » (acte II, scène 2 - le thème sera repris dans la scène 1 de l'acte IV). Robert est bien sûr à la tête dudit tribunal, et, regrettant d'en devoir user ainsi (« J'étois né pour faire des heureux, \& je porte la terreur dans la société », acte II, scène 1), confie au roi les raisons personnelles qui le poussent (le rejet par les êtres aimés), sollicitant une terre isolée... Nouveau Robin des Bois, il se félicite des innocents que l'on épargne ou que l'on protège dans le feu des combats, et cette philanthropie conduit aussi l'usage du butin, qui rappelle les buts des sociétés fondées depuis Paris dans les années 1780 : aide aux orphelins, aux pères de famille emprisonnés, aux veuves avec enfants à charge, aux dots des jeunes filles pauvres, aux paysans frappés par des calamités naturelles (acte $\mathrm{V}$, scène 2). Mais les statuts de la troupe ne prévoient-ils pas de "protéger le faible contre la tyrannie des grands », de combattre « l'impuissance des lois et l'injustice de leurs ministres » (acte II, scènes 3 et 4), voire de réunir le genre humain autour de principes réformateurs, que les contemporains peuvent aisément rapprocher de la Déclaration des droits de l'homme et du citoyen : « Ne bornons pas nos exploits à punir les oppresseurs de notre patrie; rendons nos bienfaits universels; analysons les droits que la nature a départi à notre espèce; adressons le manifeste à tous les peuples courbés sous le joug des tyrans, à tous les hommes capables de sentir la dignité de leur être » (acte IV, scène 1)? Et, lorsque entourés par les soldats et refusant la reddition et le pardon que leur propose un aumônier, les brigands s'élancent sous le feu des mitrailles, c'est au cri de «La liberté ou la mort! » (acte IV, scène VIII). La fin consacre leur combat: devenu philosophe, l'empereur n'agit pas autrement que si Nicodème l'avait convaincu, et, prétendant « réformer par la justice » les abus que les brigands punissaient par la force, leur offre son pardon. Peut-on faire l'amalgame avec une quelconque clémence de Louis XVI? 
En tout cas, Robert ne signe nulle allégeance à d'autre souverain que la loi : "Vouons à la défense de la patrie \& des lois qu'on va réformer le courage que nous avons mis à les venger quand on les outrageait » (acte $\mathrm{V}$, scène 9).

Les didascalies transportent pourtant l'action, selon les usages littéraires de la critique politique, dans un ailleurs improbable, souvenir des noires forêts franques vers lesquelles Sieyès, dans son Qu'est-ce que le Tiers état?, proposait de renvoyer la noblesse : « La scène se passe en partie au château de Moldar, en partie dans une forêt qui est éloignée d'un quart de lieue, dans un canton de la Franconie ». Ces marges barbares, cet isolement et la forêt rêvée sont aussi des poncifs des récits de brigands car, d'acte en acte, les tribulations des comédiens, une intrigue riche d'allusions, s'accordent parfaitement avec les classiques et allégoriques fonds de scène de tout théâtre qui se respecte (le décor d'un château, la forêt, le salon, la prison devenue caverne, pour souligner soit les signes extérieurs de la féodalité soit l'impasse politique qui réduit le régime à la monstruosité, soit la dépression individuelle ${ }^{17}$ ). Les changements de décor à vue sont réputés enchanter le public : on devine qu'en l'occurrence l'utilisation de toute la gamme est aussi de la part de l'auteur une tentative de le ravir pour augmenter le nombre de représentations (mais Schiller lui-même usait de quatorze lieux différents). Dans l'acte I, le spectateur découvre donc un appartement du château de Moldar, sans plus de précision; mais dans le suivant, c'est un champ de bataille qui s'ouvre à lui, empruntant à deux types de décor :

«Le théâtre représente une forêt épaisse : dans le fond, d'un côté une plaine; des chaumières dans l'éloignement; de l'autre, des collines. Les brigands sont couchés \& endormis sous les arbres, plusieurs d'entr'eux sont blessés; l'un porte le bras en écharpe. Les trois premières scènes se passent pendant la nuit $\&$ aux premiers rayons du jour ».

Dans l'acte III, le contraste est marqué entre d'un côté le château de Moldar, de l'autre des bosquets et un jardin engazonné. On retourne ensuite définitivement à la forêt, avec un premier tableau de genre qui en dit long sur la légende des brigands, mêlant plaisirs simples des tavernes et appétences intellectuelles - on retrouvera les mêmes, blessés et expirants, pour le dernier acte, aucun des combats n'ayant envahi la scène :

(17) Olivier BARA, «L'imaginaire scénique de la prison sous la Révolution. Éloquence et plasticité d'un lieu commun », in Philippe Bourdin et Gérard Loubinoux (dir.), Les Arts de la scène et la Révolution française, Clermont-Ferrand, Presses universitaires Blaise-Pascal, 2004, p. 395-417. 
«Les brigands sont disposés par grouppes; les uns couchés à terre jouent aux dés, d'autres boivent, fument ou dorment. D'un côté sur le devant est Razman, le bras en écharpe, examinant avec attention des papiers, \& se servant de temps en temps d'un crayon qu'il tient dans sa main. De l'autre sur le devant, est un brigand qui ferme un livre, \& semble continuer une conversation avec deux de ses camarades; on voit à terre des cruches pleines de vin $\&$ des verres ».

\section{La diffusion, des professionnels aux amateurs}

Les spectateurs sont toujours aussi nombreux lors de la reprise de la pièce, en 1793. En rendant compte, l'Almanach des Muses pour l'an II de la République simplifie encore l'intrigue dans le résumé qu'il en propose : en un temps où les «riches égoïstes » sont condamnés, il prétend en apprécier le mouvement, les « ressorts romanesques », et particulièrement le rôle de Robert ${ }^{18}$. Un long rapport de police du citoyen Perrière dit clairement combien Robert, chef des brigands, plébiscité par les spectateurs, peut être compté au nombre des pièces patriotiques, mais prouve aussi la sensibilité et la réactivité des auditeurs au moindre mot, à la moindre phrase qui peuvent paraître suspects, et en l'occurrence l'interventionnisme de la mouche pour calmer certaines ardeurs. Où, en plein débat sur la Terreur et le maximum, il est question de libertés individuelles et de l'intérêt supérieur de la Nation, de la nécessité de la censure enfin, sur laquelle Perrière conclut sa missive; où l'on constate aussi les modifications de la mise en scène, la foule des combattants envahissant désormais le plateau, selon les normes du théâtre patriotique :

« On donnait hier à ce spectacle (Théâtre de la République) la pièce tant connue de Robert, chef de brigands. On peut dire qu'il n'en existe point dont l'esprit soit plus conforme à notre situation politique actuelle; elle respire la vertu, mais une vertu vraiment révolutionnaire et digne des fondateurs de Rome. Elle renferme seulement deux passages dont l'un peut être saisi par les aristocrates et l'a été, en effet, par un ou deux qui se trouvaient mêlés à cet auditoire patriote, et l'autre a paru exciter les scrupules et balancer l'opinion des patriotes. Le premier est celui où Robert, se disposant à combattre 3000 hommes avec sa troupe de 300 , compte assez sur l'effet du courage

(18) Almanach des Muses pour l'an II de la République, Paris, Delalain, 1794, p. 228 : « Imitation d'un drame qui a de la célébrité en Allemagne. Ces brigands sont des redresseurs de torts qui se comparent souvent à Hercule, et qui croient devoir suppléer par la force à l'insuffisance des loix. Ils ne pillent et n'assassinent que les puissans et les pervers; ils leur font même auparavant leur procès ». 
pour s'exposer encore à en diminuer le nombre, en donnant la liberté de se retirer à ceux qui ne se sentiraient pas assez fermes pour le combat; seulement, dit-il, ils renonceront à leur habit militaire, et je dirai, si nous sommes vaincus, que ce sont des voyageurs que nous avons dépouillés! Ce trait de générosité a été vivement applaudi, parce qu'il peut l'être par tous les partis ; mais j'ai entendu un aristocrate qui n'était qu'à deux ou trois banquettes de moi dire avec triomphe : "Ah! ce ne sont pas là des enrôlements forcés! - Citoyen, lui ai-je répondu, il est des époques pour les sociétés et des circonstances pour les hommes où nul n'a besoin d'être forcé; mais convenez que de vieux esclaves que l'on veut régénérer ont besoin d'être poussés au feu et qu'à leur retour ils sauront bon gré à ceux qui leur auront appris à retrouver le courage dans le sein du danger, et la liberté qui en est le prix". Le second de ces passages est celui où Robert, averti d'un complot qui se tramait contre lui-même, et recevant des mains du dénonciateur une lettre qui contenait les détails, se dispose à la lire; mais, s'apercevant qu'elle n'est pas ouverte : "Elle est cachetée", dit-il, saisi d'un sentiment de respect, et il la remet dans son sein, et, dans la suite de la pièce, ne la donne à ouvrir qu'à celui qui l'avait écrite. Cette conduite, excitant d'abord dans les spectateurs une admiration tacite qui semblait un blâme secret de la conduite différente tenue par les patriotes à diverses époques d'insurrection, est bientôt couverte d'applaudissements commencés par des patriotes moins purs et moins éclairés. 'En effet, dis-je à mes voisins, il n'est ici question que des seuls intérêts de Robert, et il est bien le maître de se traiter lui-même comme il lui plaît; mais, quand il s'agit de ceux d'une grande nation, pourquoi se laisserait-elle arrêter tout entière par une considération toujours inférieure à celle du bien public, et dont la violation, après tout, ne peut compromettre que le scélérat qui en avait fait l'abri de son crime? À moins que l'on ne suppose que la vue d'une telle générosité, en agrandissant l'âme du peuple, ne produise dans une révolution un bien double et triple du mal que l'on aurait évité par une conduite opposée : je ne croirais cependant pas sûr pour la France d'user, dans toutes les circonstances, d'une pareille générosité, et l'expérience a prouvé qu'elle n'a déjà été que trop la dupe de ces beaux mouvements. Je ne blâme cependant pas un auteur qui les insère dans son ouvrage : là, la morale ne saurait être trop parfaite, puisque l'homme, dans les combats de ses passions et de ses intérêts, est réduit à l'altérer toujours beaucoup trop, visiblement condamné par la nature de son être à ne connaître que la perfection qu'en théorie" $\gg{ }^{19}$.

(19) Pierre CAron, Paris pendant la Terreur, Paris, Alphonse Picard, 1910. Rapport de police du 8 septembre 1793 . 
Ayant l'imprimatur du pouvoir et des spectateurs parisiens, Robert, chef de brigands, entame une carrière provinciale. On apprécie à Grenoble, par exemple, la nouveauté du sujet, son pittoresque et son énergie, jusqu'à la violence, l'ambivalence des sentiments qui font passer de la pitié à la terreur : "Qu'on ajoute à cela du spectacle, de grands mots déclamatoires, du tapage, des coups de pistolet, et voilà une réussite expliquée, si elle n'est pas justifiée aux yeux du bon goût et de la saine critique $»^{20}$. La Provence connaît plusieurs représentations sous le Directoire : en brumaire an IV à Marseille, le succès éprouvé au Théâtre de la rue du Pavillon se poursuit au Grand-Théâtre, qui assurera encore une reprise en l'an VI, tandis que la salle de Toulon en a fait pareillement un élément de sa programmation ${ }^{21}$. On sait cependant que la pièce n'a jamais créé l'unanimité, et un autre rapport de police, de thermidor an IV, très lapidaire, soulignera les incompréhensions qui perdurent - mais sans doute sont-elles désormais autres :

«La Martelière, Robert, chef de brigands. Rapport du 8 thermidor [an IV]. Spectacles. Le bon ordre y a régné; Compère rapporte néanmoins qu'au Théâtre de l'Opéra-Comique national, le spectacle a été interrompu au troisième acte de la pièce des Brigands par quelques citoyens turbulents auxquels certains vers ne convenaient pas. Il ajoute que ceux-ci ont été vivement rappelés à l'ordre et que le calme s'est rétabli aussitôt $\gg^{22}$.

Peu importe : du théâtre professionnel, la pièce a déjà gagné le répertoire des amateurs. Ouvrant la boîte des souvenirs privés, George Sand se souviendra avec précision de Robert, chef des brigands, dans l'Histoire de ma vie ( $1^{\text {ère }}$ partie, chapitre VII). En l'an VI, son père, qui avait vingt ans et serait bientôt touché par la conscription, jouait le rôle de Robert en sa demeure de La Châtre, et mettait en scène ses partenaires; la mère de Charles Duvernet, grand ami de George Sand, incarnait Sophie, l'héroïne. Tous les deux étaient membres de l'une de ces sociétés drama-

(20) Ducorn, « Souvenirs du théâtre de Grenoble », dans Bulletin de l'Académie dephinale de Grenoble, 1856, p. 190.

(21) Journal de Marseille, $\mathrm{n}^{\circ}$ 42, 6 brumaire an IV (28 octobre 1795), p. 384-385 : « Le Drame lyrique du Brigand a été joué sur la grand Théâtre de cette ville, \& les applaudissemens qui l'avoient accueilli au Théâtre de la rue du Pavillon l'ont suivi à l'autre spectacle »; L'Anti-Royaliste, $n^{\circ} 24,29$ pluviôse an VI (17 février 1798), p. 91 : « On a joué ces jours derniers, au grand théâtre de Marseille, la pièce intitulée Robert, chef des brigands ou l'Homme vertueux »; Archives municipales de Toulon, Délibérations municipales, 10 frimaire an VI (30 novembre 1797). Je remercie Stephen Clay de ces renseignements.

(22) Alphonse Aulard, Paris pendant la réaction thermidorienne et sous le Directoire, Paris, Le Cerf, 1898-1903. Rapport de police du 25 juillet 1795. 
tiques si appréciées de la bourgeoisie provinciale et tant encouragées par les clubs révolutionnaires ${ }^{23}$. Celle de La Châtre, forte d'un orchestre, se donnait à voir en la circonstance dans la salle en gradins de l'ancien club jacobin, ci-devant couvent des Carmes. Les amateurs avaient beaucoup hésité à monter Robert, chef de brigands, non qu'ils n'en partageassent les idéaux réformateurs, mais le rôle titre les effrayait. Ils avaient finalement engagé pour les y aider les prisonniers de guerre hongrois et croates en cantonnement dans le district (pied de nez à la vie : le père de Sand sera quelques années plus tard prisonnier des Croates ...) : «On leur fit comprendre qu'après la bataille ils devaient paraître blessés; ils se concertèrent si bien et y mirent tant de conscience qu'à la représentation on les vit sortir de la mêlée boîtant tous du même pied ». Si l'on ne sait rien des décors, créés pour la circonstance, les costumes nous en disent assez sur les bouts de ficelle que devaient rattacher ensemble les comédiens d'un soir, mais aussi sur la manière dont leur imagination courait pour représenter un brigand, germanique de surcroît, fort du produit de ses rapines accumulées, éloigné du goût des salons sinon dans le souci de paraître, et empruntant aux deux règnes durant lesquels la réalité avait le mieux, et pour longtemps, nourri la fiction, ceux de Louis XIII et de Louis XIV :

« Le costume de Robert consistait en une pelisse de hussard attachée au cou par une agrafe de diamants, un pantalon collant rouge, une ceinture en laine remplie d'une effroyable garniture de pistolets et de poignards, des bottes Louis XIII, un ample manteau en laine rouge bordé de martre, un bonnet de fourrure. Maurice de Molda (le François de Moor de Schiller), représenté par M. Delatouche père, était revêtu d'un habillement non moins curieux : habit Louis XIV, manteau de satin blanc, culotte courte, bas de soie, écharpe et chapeau à la Henri IV. Madame Duvernet (Sophie) avait une robe à queue soutenue par une brillante ceinture pailletée, et un long voile blanc tombant jusqu'à terre ».

«La République s'était parée de ce titre et ne le porta pas longtemps, mais l'instinct du vrai et du juste n'était pas détruit avec des formes passagères. Ces formes étaient là comme de vieux costumes de théâtre qu'on rajeunit pour les faire servir à d'autres rôles, à de nouvelles fictions. Mon père ceignit avec joie la ceinture garnie de pistolets du chef des brigands, ses jeunes amis (plusieurs avaient déjà servi la République comme volontaires) s'enrôlèrent dans sa troupe, et tous ensemble, oubliant qu'ils jouaient une pièce jacobine, rêvèrent de combats et de prodiges. Ces bri-

(23) Philippe Bourdin, « Le théâtre, les amateurs, la Révolution », dans Philippe Bourdin et Gérard LouBinoux, La scène bâtarde, op. cit., p. 241-256. 
gands n'étaient plus des sans-culottes futurs, c'étaient des maréchaux en herbe. Robert allait s'appeler Bonaparte ».

\section{L'entrée dans la postérité}

L'appropriation de l'intrigue, dont la longévité sur les tréteaux est exceptionnelle, se fait par l'intermédiaire de gens très différents, dont le vécu révolutionnaire l'est tout autant. Robert, chef de brigands, est suffisamment réputé pour devenir une évidence dans la conversation courante, fût-ce au prix de quelque confusion avec le Brigand de Schiller et d'un évitement des sous-entendus politiques premiers de la pièce. Mais une lecture littérale en dit tout aussi long sur les réemplois du mot «brigand », éternel chef d'accusation politique entre adversaires. Laure Junot d'Abrantès rapporte ainsi ce dialogue entendu à l'heure de la Première Restauration dans le salon de la duchesse d'Angoulême, quand il est de bon ton de moquer les armées napoléoniennes et leurs généraux : «-Et on appelle cela une armée, disait une jeune femme [...]. C'est la troupe de Robert, chef de brigand ... avec cette différence que Robert était un grand seigneur d'Allemagne, et que leur Bonaparte est le fils d'un méchant juge de village $»^{24}$. L'impression est encore plus forte sur Charles Nodier. On sait la fascination qu'exercent le crime et sa punition (tôt vécue au travers des exécutions capitales) sur ce fils de président du Tribunal criminel du Doubs. Il transcrira les ombres de la terreur qui le hantent, et qui sont augmentées par les drames personnels, dans Le Voleur, roman de révolte contre la société qui exalte un primitivisme égalitaire envisagé comme l'âge d'or du monde, selon une tradition chère aux Lumières, avec des références explicites à la Bible, à Dante, à Montaigne, à Goethe et à Schiller, auquel il emprunte partie de l'intrigue amoureuse ${ }^{25}$. Ne méconnaissant

(24) Laure Junot D’Abrantės, Mémoires sur la Restauration, Louis Hauman et Cie, Bruxelles, 1835, tome 2, p. 223.

(25) Jean Nicolas DE SURmONT, URL : http://www.republique-des-lettres.fr/1436-charlesnodier.php. Nodier utilise un procédé de fiction éditoriale, se présentant comme le traducteur du texte. Le brigand de l'histoire est Lazare, ermite français, taciturne et mystérieux, devenu chef des voleurs dans une société qui se trouve être un lieu d'hypocrisie, d'abus et d'injustice. Les autres personnages sont la jeune Maria, qui trompe le major Verner pour le baron Guillaume Ribing. Verner et Lazare, bien qu'affichant des tendances suicidaires, sont sauvés par leur révolte et par leurs rêves. Paul, fils de Maria et de Verner, possède en lui le salut alors que Maria, la victime sacrificielle, rachète les brigands. Incapable de concevoir le mal et la dissimulation Paul est choisi par les brigands comme cible. Ils le séquestrent parce que l'un d'eux est amoureux, comme dans Les Brigands de Schiller, de la fiancée de Paul. Lui, prisonnier comme l'a été Nodier, découvre la misère de ses co-détenus. Tout est occasion pour Nodier d'évoquer la Justice par l'intervention d'un Dieu réparateur, de développer des sujets comme le suicide, l'héroïsme, la gloire, la corruption, etc., ou d'évoquer (chapitre V) une association secrète faisant implicitement référence à la Société des Philadelphes dont il a été membre. 
aucunement les errances et reconversions des émigrés français à Trieste, Nodier ne dédaignera pas d'y installer l'intrigue d'un autre roman dont le héros est un bandit, Jean Sbogar ${ }^{26}$. Dans ses Souvenirs de la Révolution et de l'Empire, il fait explicitement référence à Robert, chef de brigands, pour rapporter le récit aux formes de brigandage exercées par les bandes royalistes du Directoire contre les malles-poste du Trésor public, vols dont il se déclare solidaire :

« Je ne dis pas, dieu m'en garde! que les compagnies qui furent chargées de ces horribles opérations se composèrent de l'élite du parti. Personne ne me croirait; c'étaient, en général, des jeunes gens perdus de dettes, de débauches, de crimes, qui se réfugieraient au hasard sous le premier étendard venu, où ils pouvaient trouver quelque garantie d'impunité, ou quelque solidarité de dévouement et de sang. Tout le monde ne sait pas au juste ce que le sentiment de l'honneur peut produire de grand dans le cœur d'un brigand désespéré, qui croit s'ennoblir en s'associant à une noble cause. Près de ces misérables, on comptait quelques-uns de ces esprits exaltés, si communs alors, que l'entraînement d'une opinion décidait moins que l'appât d'un danger aventureux. Quelques-uns [...] faisaient ce métier en amateurs, et pour jouer leurs têtes dans des exploits de bandits qui ne leur paraissaient pas condamnables aux yeux de la morale. J'ai vu beaucoup de ces malheureux, j'ai vu surtout ceux dont il est question ici, et je les vois encore, téméraires, exaltés, jusqu'au délire, passionnés jusqu'à la fureur; mais incapables de faire tort d'un denier au trésor d'un riche, et prêts à racheter de leur sang les larmes d'un enfant; semblables enfin à ces compagnons de Charles Moor ou de Robert chef de brigands, qu'ont illustrés la tragédie et le mélodrame $\gg^{27}$.

Les critiques littéraires sont moins amènes avec le travail de La Martelière. Prosper de Barante, qui pour l'occasion l'associe avec la traduction ultérieure d'Auguste Creuzé de Lesser (Les Voleurs, tragédie en prose en cinq actes « imitée de l'allemand », Paris, an $\mathrm{III}^{28}$ ), juge que l'un et l'autre ne retiennent que l'intérêt dramatique des situations, rendent beaucoup plus active la bande de grand chemin, dont ils finissent par trans-

(26) Marie-Catherine Huet-Brichard, « Brigandage et apories de l'histoire : Jean Sbogar de Charles Nodier », colloque de Toulouse, Brigands et brigandage. Criminalité, violence et protestation politique (vers 1750-vers 1850), 24 et 25 mai 2007.

(27) Charles Nodier, Souvenirs de la Révolution et de l'Empire, Paris, Charpentier, 1850, tome 1, p. 127-128.

(28) Joseph-Marie QuÉRARD, La France littéraire, ou Dictionnaire bibliographique, Paris, Firmin-Didot, tome 8, 1836, p. 517. 
former les membres en juges et exécuteurs d'un tribunal secret, jusqu'à leur donner "une existence régulière et officielle », et croient ennoblir le chef des brigands en lui ôtant tout sentiment de haine et de doute ${ }^{29}$. Il aurait pu rajouter que ces imitateurs imaginent une fin heureuse pour se conformer au goût de l'époque, tout comme leur contemporain Ducis transforme les dénouements des drames shakespeariens. Germaine de Staël prétend que La Martelière n'a conservé que «la pantomime de l'action », faisant disparaître l'originalité des caractères ${ }^{30}$. Dans l'Histoire de ma vie, George Sand, qui visiblement a lu la précédente et lui emprunte beaucoup sans la nommer, revient sur la signification de la traduction française de Schiller, relue à la lumière de l'an $\mathrm{II}^{31}$. Pessimiste sur une société qu'il juge perdue, Schiller se détournait à l'évidence pour la régénérer de la torche et du glaive, et Sand, qui le suit, de conclure :

«Une œuvre de vie ne peut pas sortir des mains du bourreau, que sa hache soit bénie par l'Inquisition ou par Calvin, par Richelieu ou par Marat, par le pouvoir sans croyance ou par la révolte sans entrailles ».

N'avait-elle pas confondu plus tôt un brigand reprochant ses scrupules à Charles De Moor avec «les Carrier et les Fouquier-Tinville, monstres inévitables dans les révolutions délirantes »? Admiratrice du drame allemand, la romancière juge de petite eau, une eau de rose, sa transposition française par La Martelière, insoucieux de l'esprit et des leçons de l'original. Robert n'est pas le criminel qu'était Charles Moor, « et s'il règne par la terreur, c'est parce qu'il lui plait de se faire craindre et d'avoir de grandes moustaches rousses », tandis que ses compagnons sont d'une éducation irréprochable. Chez Schiller, ils jetaient au feu un enfant qui avait froid; chez La Martelière, ils se brûlent la barbe pour le sauver des flammes et le mettre en nourrice. La veuve, le vieillard, l'orphelin sont en bref autant de bénéficiaires d'une philanthropie active, ou d'une civilité volontiers étendue au beau sexe. Les seules cibles sont les usuriers, les concussionnaires, mal défendus par leurs obligés, amis et courtisans, tous prétendus aussi lâches qu'est vil celui qui est exécuté, un discours dans lequel Sand veut voir la préfiguration des accents de la Montagne, une Montagne à laquelle elle admet qu'elle aurait fort bien pu appartenir, sûre cependant quant à elle que « le sang des hommes divisés d'opinions n'est pas toujours nécessairement impur de part ou d'autre ».

(29) Prosper de Barante, op. cit.

(30) Germaine DE STAËL, op. cit.

(31) George SAnd, Euvres autobiographiques, op. cit., 1970, p. 165-175. 
Prétendument protégé par Hercule, Robert, auréolé de ses exploits généreux, voit la société se réconcilier avec lui, sa maîtresse l'épouser par amour, son père le bénir, les populations le porter en triomphe, l'empereur d'Allemagne l'accueillir et placer ses hommes à la tête de l'administration et de l'armée. La violence qu'il a exercée avec circonspection a donc été le gage d'une régénération, comme la Terreur y prétendra. Et la fin justifie les moyens... une doctrine que ne reniera pas Bonaparte, selon Sand qui, en attendant, fait de Robert un Robespierre.

"C'est-à-dire que d'une œuvre de scepticisme ou de douleur [La Martelière] fit, sans se gêner, une œuvre de foi et de triomphe : Ce ne fut plus le cri d'agonie de l'Allemagne expirante, ce fut le chant de guerre de la France renouvelée. Les étudiants penseurs et exaltés de la Germanie devinrent des philosophes des clubs parisiens, et tout en leur conservant leurs noms allemands, en les transportant même du dix-huitième au quinzième siècle de l'empire germanique, l'auteur en fit des jacobins idéalisés, des septembriseurs philanthropes. Il résulta de cet amalgame (plus vraisemblable au fond qu' on ne croirait) un drame tout à fait bizarre, parfois sublime et parfois ridicule, jamais odieux; et ceci est le plaisant de l'affaire ».

\section{Les brigands contrefaits}

\section{À la recherche d'une improbable suite}

Ces approximations et transgressions assumées, et fort des rentes ainsi constituées, La Martelière imagine en 1793 un drame nouveau en cinq actes, Le Tribunal redoutable, ou la Suite de Robert, chef de brigands. Robert est désormais souverain du comté de Moldar. Trois de ses anciens compagnons de brigandage (Wolbac, Falker, Forban) sont devenus ses conseillers, tandis que son frère Maurice continue de comploter contre lui, comme les cadets de France l'ont fait dans l'histoire. Dans l'acte I se réunit donc une sorte de cour aulique : "Le théâtre représente la salle du conseil dans le château de Moldar. Des sièges sont placés de distance en distance ». Robert, sans père ni épouse (Sophie est morte en accouchant), n'a pu atteindre l'amour familial auquel il aspirait, et il se dit rongé par son passé d'assassin : ces souvenirs sont ravivés par Adolphe de Marbourg, dont il a fait exécuter le père, et par sa femme Julie. Seuls les instants où il prodigue sa bienfaisance le soulagent, malgré l'amour que lui manifeste le peuple, notamment pour son anniversaire, devenu jour de fête nationale (acte I, scène 1). Les habitants du comté de Marbourg demandent un rattachement au sien, pour vivre sous ses justes lois, ce qui, évidemment, 
rappelle aux spectateurs les cas de l'Alsace ou du Comtat Venaissin (acte I, scène 3). Robert, qui refuse de croire en une tyrannie héréditaire, propose au contraire de mettre à leur tête Adolphe de Marbourg, mais on lui apprend qu'il est mort et qu'il est accusé d'en être le meurtrier (acte I, scènes 3 et 4). Dans l'acte II, on retrouve Adolphe, qui fait courir ce faux bruit, dans un décor dont les inscriptions rappellent les usages révolutionnaires des mises en scène publiques: "Le théâtre représente l'intérieur d'une caverne, deux monumens formés de pierres sont aux deux côtés de la porte, on lit au-dessus de l'un ces mots : À la vengeance; au-dessus de l'autre, ceux-ci : À la reconnaissance ». Adolphe est seul, "assis sur un morceau de rocher, et fixant tour à tour les deux monuments ». Si le public n'avait pas reconnu la prison du Temple, le proscrit rappelle que, comme Louis XVII, il ne peut compter que sur la bonté d'un vieillard qui le connaît à peine, qu'il est victime du " fer des factieux » (acte II, scène 2). Robert va à sa rencontre sans se dévoiler, lui propose son aide et l'invite au château. Adolphe, encouragé par un Maurice qui peint son frère sous les traits les plus noirs, y voit le moyen de se venger du bourreau de son père (acte II, scène 4). L'acte III marque la fin d'un règne, la prise de toutes les Bastilles: "Le théâtre représente d'un côté un vieux château à demi ruiné, situé à l'entrée d'une forêt ", le côté sombre et tragique de l'Ancien Régime, qui s'oppose à la clairière, soit la lumière des temps nouveaux. Maurice, torturé par les apparitions spectrales de son propre père, parvient à convaincre, par un intermédiaire, Wolbac que Robert a fait enlever Julie pour assouvir ses désirs; Wolbac la délivre et reconnaît sa sœur (acte III, scènes 4 et 5). Son dégoût pour Robert, qu'il communique aux autres conseillers, grandit d'autant, et tous s'érigent en tribunal contre leur chef. La mise en scène de l'acte IV inscrit l'action dans un espace sacré, un cimetière dont la tombe honorée pourrait être celle de Saint-Louis : «Le théâtre représente un vaste paysage: au milieu est le tombeau du vieux Moldar, sur le devant duquel est écrit en gros caractères : Il ne fut heureux que du bonheur de son peuple, plus bas, L'année MDXXXVII. De gros chênes ombragent ce monument ». La justice sera justement rendue sous ces arbres. Tout, selon les didascalies, se déroule avec le sérieux et la solennité que réclament les processions et les procès révolutionnaires :

«La marche commence par un détachement des gardes du prince, qui va se partager les deux côtés du théâtre.

Ce détachement est suivi de deux pages qui portent sur un coussin le poignard des vengeances; ils le déposent au milieu de la scène, \& vont ensuite se placer derrière Robert. 
Ensuite, les différens membres du tribunal, suivis de Robert.

La marche est fermée par des gardes qui vont occuper le fond.

Il est de toute nécessité de donner à cette scène un appareil assez pompeux pour répondre à l'idée qu'on a pu se former d'un tribunal si extraordinaire $\gg$.

En vain le peuple a-t-il été sollicité pour se plaindre de son souverain. Wolbac, qui voit son accusation s'effondrer au fur et à mesure que les mensonges de Maurice éclatent au grand jour, prouve combien l'erreur peut entraîner partie d'une cour à rejeter celui que la veille elle adorait - et l'on pense aux aristocrates à talons rouges... Le dernier acte enfin, celui de l'apaisement, nous ramène à une sociabilité des Lumières, comme si tout devenait possible dans un château apparemment reconstruit : «Le théâtre représente un superbe sallon dans le château de Moldar ». Robert et Adolphe jurent de régner ensemble sur la Germanie (acte V, scène 3 ) et le premier déjoue une conjuration ourdie par Maurice (acte V, scène 7) puis gracie une fois encore ce dernier, usant d'un droit qu'il prétend attaché à son rang. Mais Maurice préfère se suicider (acte V, scène 8).

Sans doute La Martelière n'a-t-il pas songé un instant à trahir Schiller, qui avait toujours envisagé d'écrire une suite sans jamais s'y astreindre - il souhaitait notamment mieux dégager la signification morale des Brigands. Aucune imitation n'était donc cette fois possible et d'aucuns trouveront bien fade le résultat, comparé au premier volet: « comme il n'avait plus Schiller pour guide, et qu'il lui fallait inventer, ce qu'il inventa ne valant pas ce qu'il avait copié, la suite de Robert ne produisit qu'un mince effet $»^{32}$. À Grenoble, même par antiphrase, on ne dit pas autrement du contenu : «N'ayant ni le peu de beautés ni les nombreux défauts de son frère aîné, il n'en partagea point le succès et ne fut représenté qu'une ou deux fois $»^{33}$. Publiée à Paris, en 1793, toujours chez Maradan et Barba, la pièce a été donnée quatorze fois à partir du 10 novembre 1792, au Théâtre du Marais. À partir de la quatrième représentation, le titre est devenu Robert républicain, ou le Tribunal redoutable. Sans doute fallait-il souligner cette option républicaine, qui est fort peu évidente, sinon aberrante. Car il s'agit bien de maintenir une royauté, et nul en 1793 ne pouvait s'y tromper : les souverains mis en scène par La Martelière ont les vertus des panégyriques, magnanimité,

(32) Nicolas Brazier, op. cit., p. 11.

(33) Ducorn, « Souvenirs du théâtre de Grenoble », art. cit., p. 191. 
courage et générosité, leur rapport au peuple est fondé sur le plébiscite. $\mathrm{Au}$ début du $\mathrm{Xx}^{\mathrm{e}}$ siècle encore, Maurice Albert prétendra même voir la réincarnation de Louis XVI dans le chef des brigands, qu'il avait du reste mal identifié, le prénommant Adolphe... ${ }^{34}$. Aucune phrase ressortant du discours révolutionnaire ne vient cette fois ponctuer le propos de La Martelière. Là est vraisemblablement l'une des causes de l'échec de ce second volet.

\section{Les « brigands " royalistes}

D'autres sont à chercher dans la production d'auteurs concurrents, qui ont cherché à détourner à leur profit la vogue du premier Robert. Ainsi le Théâtre de Molière donne-t-il pour vingt représentations à partir du 18 mai 1793 Encore une caverne, ou Le Brigand vertueux, trois actes en prose. Il faut compter aussi avec les évolutions sémantiques qui affectent le mot « brigand » : il désigne clairement désormais les ennemis de la République, et plus précisément les Vendéens, et est décliné en ce sens dans plusieurs créations théâtrales. Ainsi dans Les Brigands de la Vendée, opéra vaudeville, deux actes en prose, " avec combats et incendie », de Mathurin-Joseph Boullault, de la section du Temple. Jouée d'abord chez Lazzari, au Théâtre des Variétés, le 3 octobre 1793, la réputation vite acquise de cette pièce lui vaut d'être représentée trente fois du second trimestre 1793 jusqu'à la fin de l'année 1794, puis neuf autres au Théâtre de la Gaîté au second semestre 1794. Éditée par la citoyenne Toubon à Paris, en 1793, elle est précédée d'une déclaration du 4 octobre 1793 précisant qu'elle pourra être jouée sur tous les théâtres de la République, preuve d'une reconnaissance et d'un appui officiels qui la font clairement entrer dans le répertoire patriotique. Le Journal de Paris, qui fait le compte rendu des premières soirées données à la Gaîté intitule pourtant le spectacle La Noce interrompue par les brigands de la Vendée, créant la confusion avec une autre pièce, La Noce interrompue. Dans les faits, le mariage existe bien, mais il clôt l'intrigue, alors que les «brigands » sont tous prisonniers ${ }^{35}$. L'ennemi intérieur est également clairement fustigé dans Les Chouans de Vitré, fait historique en un acte en prose par François Fouques Desfontaines (1733-1825), créé le 12 juin 1794, et qui tient vingt-deux représentations au Théâtre du Vaudeville, dans Les Chouans, ou la républicaine de Malestroit, fait historique en

(34) Maurice Albert, Les théâtres des boulevards (1789-1848), Paris, 1902, réed. Slatkine Reprints, Genève, 1978, p. 104.

(35) André Tissier, op. cit. 
un acte en prose avec vaudeville, de François-Marie Riou et Joseph Pain, pièce inaugurée à Brest le 6 novembre 1794, puis à Paris le 29 juillet 1795 et pour vingt représentations à l'Ambigu-Comique, ou dans Les Brigands de la Vendée. Toutes ces créations offrent aux simples lecteurs des affiches une géopolitique sommaire en laquelle ils retrouvent les catégories d'un discours militant simplificateur. Dans un paysage de guerre volontiers reconstruit, destiné à inspirer la mobilisation quotidienne, civisme et philanthropie sont à l'honneur et permettent de mieux distinguer l'adversaire confondu sous le masque de l' « émigré » ou du « brigand » tandis que sont exaltés, dans un cadre favorisant souvent la campagne, donc la nature, les vertus privées ou familiales, l'éducation civique et les rouages du gouvernement révolutionnaire.

Le tout est propice à la naissance de héros, sortis vainqueurs du combat contre les monstres. Tel est l'argument principal d'une création faite au Théâtre du Vaudeville en messidor an II, Le Canonnier convalescent, de Radet :

«Anecdote touchante d'un jeune canonnier, qui, fait prisonnier par les brigands, et fusillé par eux, se traîne, tout sanglant, dans une commune voisine. Là, une jeune fille le rencontre, étanche son sang, va chercher les habits de son père, dont elle le couvre, et parvient, à force de soins, à lui faire recouvrer la santé. Une société populaire, instruite de ce trait, envoye une couronne civique à la jeune fille, et un sabre au canonnier $»^{36}$.

L'Hérö̈ne de Mithier, vaudeville en un acte, fait historique de Antoine Vée, dit Duchaume (1766-1842), et Barral, prétend relater un fait historique que Léonard Bourdon consigne dans son Recueil des actions hérö̈ques et critiques des républicains français ( $\mathrm{n}^{\circ} 3$, XXVIII, p. 25,15 brumaire an II -5 novembre 1793). Ainsi le résume l'Almanach des Muses pour l'an III (p. 28) : « Trait de courage qui a eu lieu lorsque les brigands s'emparèrent de Mithier. Une jeune femme, assise dans sa boutique, entourée de ses enfans, un pistolet ajusté sur un baril de poudre, menace les scélérats de faire sauter la maison, s'ils ne se retirent ». La pièce a les honneurs du Vaudeville - toujours lui - le 20 août 1794 et compte dix-neuf représentations au deuxième semestre. Viala, exalté à l'Opéra-Comique ou au Théâtre lyrique des Amis de la Patrie le 13 messidor an II ( $1^{\text {er }}$ juillet 1794$)^{37}$, et davantage encore

(36) Ibid., p. 28.

(37) Agricole Viala ou le héros de treize ans, D’Audouin et PORTA; Le Jeune héros de la Durance ou Agricole Viala, de PHILIPPON et JADIN. 
Bara $^{38}$, dont on sait les sources d'inspiration qu'ils ont été pour les peintres, incarnent mieux encore ces héros dont le dévouement ou la jeunesse trop tôt fauchée n'entament en rien l'avenir d'une République qui se nourrit de leur postérité et de leur lutte à mort contre les « brigands ». Briois, avec $L a$ Mort du jeune Bara ou une journée de la Vendée (théâtre de la République, 15 floréal an II - 4 mai 1794) ne met pas directement en scène la guerre de Vendée, les actions de Charrette, mais les rapporte à travers différents récits issus des lettres de Bara ou des journaux, lus par un vieux militant jacobin, autant de filtres qui favorisent l'usage d'un vocabulaire convenu pour vanter l'union des générations, de « la divine Montagne, où sont les vedettes qui ne dorment jamais », contre les « brigands » vendéens (scène 12) ${ }^{39}$.

\section{Les « brigands » jacobins}

Après le 9 Thermidor, après les grands procès qui amènent par exemple Carrier à la guillotine en décembre 1794, et en réaction aux journées de germinal ou de prairial an III, le mot est retourné contre lesdites vedettes. Le travail a été favorisé par la presse et les pamphlets, à la poursuite de « la queue de Robespierre »; la violence du verbe a notamment renvoyé à leur monstruosité affirmée, à leur animalité supposée les représentants du peuple, les a relégués aux profondeurs d'une caverne, loin des lumières de la raison, pénitence des cris, des pleurs, du sang qu'ils ont provoqués, ou qui sont du moins complaisamment rapportés ${ }^{40}$. Les Jacobins du 9 Thermidor et les brigands, ou les Synonymes, au titre sans équivoque, donne le ton à partir du 26 mars 1795 . Il s'agit d'un opéravaudeville en un acte, et ces appellations de genre, appels publicitaires mis à part, tranchent aussi avec les drames revendiqués de La Martelière : il faut marquer par le rire prétendu (car les effets comiques sont rares, voire inexistants) la rupture politique et sociale. L'œuvre cependant ne connaît

(38) Citons par exemple les œuvres de LEVRIER-CHAMPrion (Joseph Bara, fait historique en un acte, Opéra-Comique, 17 prairial an II - 5 juin 1794), et de LÉGER et JADIN (L'Apothéose du jeune Bara, théâtre Feydeau, 17 prairial an II).

(39) Philippe Bourdin, « Briois ou les infortunes de la vertu politique », dans Jean DeLinière (sous la direction de), Images et clichés du monde rural européen au dix-huitième siècle, Oxford, The Voltaire Foundation, 1995, p. 123-137.

(40) Michel BiARD, « Après la tête, la queue! La rhétorique antijacobine en fructidor an II vendémiaire an III », dans Michel VovelLE (dir.), Le tournant de l'an III. Réaction et Terreur blanche dans la France révolutionnaire, Paris, CTHS, 1997, p. 201-214; du même, « Les voix de la déraison? Les représentations de la violence exercée par les "proconsuls" révolutionnaires (1793-1795) », dans Philippe Bourdin, Jean-Claude CARon, Mathias Bernard (dir.), La Voix et le geste. Une approche culturelle de la violence socio-politique, Clermont-Ferrand, Presses universitaires Blaise-Pascal, 2005, p. 49-68. 
pas le succès : elle est jouée au Théâtre du Palais (Cité-Variétés) trois fois au premier semestre 1795, puis au théâtre des Variétés-Égalité quatre fois à partir du 28 mars. Il en va tout autrement avec le fameux Intérieur des comités révolutionnaires, ou les Aristides modernes, de Ducancel, comédie en trois actes en prose, représentée pour la première fois à Paris, au Théâtre de la Cité-Variétés, le 8 floréal an III (27 avril 1795), et publiée la même année chez Barba. L'auteur, en note préliminaire, précise qu'il ambitionne «le tableau malheureusement trop fidèle des brigands qui ont si longtemps désolé la patrie », la monstruosité n'étant pas tant désormais dans les caractères théâtraux que dans les comportements politiques dénoncés. L'un des principaux rôles est celui de Dufour père, négociant persécuté par les membres d'un comité révolutionnaire dont il a fait lui-même partie, et au sein duquel ses adversaires portent tous des noms romains (Aristide, Caton, Scaevola, Brutus ou Torquatus), la déchristianisation et la dérision aidant, puisque tel laquais escroc, tel rempailleur de chaise, tel ancien portier se font ainsi sages législateurs - un procédé littéraire que l'on retrouvera bien plus tard, encore détourné, dans le Pauvre Bitos d'Anouilh. Or, Dufour, déclaré suspect par le comité, use de la même rhétorique que son auteur pour désigner ses adversaires, qui au fil des scènes vont dérober argent et biens précieux à leurs victimes : «Ils ne savent pas, les brigands, que j'ai les yeux ouverts sur les crimes qu'ils méditent »; et son fils, garde national comme lui inquiété, de renchérir : "Les monstres ne vous assassineront pas, dussai-je moi-même en purger la terre. Je cours de ce pas à la tribune imprimer sur le front de ces brigands le cachet de l'ignominie » (acte I, scène 12). Quand on lui reprochera de ne pas être jacobin, il répondra encore : « J'aime la justice, je chéris l'humanité, je hais le brigandage » (acte II, scène 7). Et tandis que l'un et l'autre, en vain recherchés par le comité, seront déclarés émigrés, c'est $\mathrm{M}^{\mathrm{me}}$ Dufour qui rajoutera : "Il seroit peut-être permis à la vertu persécutée de fuir des lieux infestés par le brigandage » (acte III, scène 3 ). La réitération du terme englobe donc dans la dénonciation et la Terreur et les sociétés populaires et enfin les individus qui les servent dont Robespierre, Saint-Just et Couthon paraissent les mentors (acte III, scène 6). Que leurs têtes tombent et au final est affirmé : " le règne des brigands est anéanti » (acte III, scène 9).

C'est dans cette même veine que l'on trouve Le Brigand, drame en trois actes de François Hoffman (1760-1828), avec musique de Rodolphe Kreutzer (1766-1831), publié à Paris, chez Huet, en l'an III. La pièce est donnée à l'Opéra-Comique, salle Favart, pour la première fois le 7 thermidor an III (25 juillet 1795) et pour dix représentations. Il s'agit là encore 
d'un drame à sauvetage (un type de récit emprunté au roman noir anglais et qui fait le succès des salles Favart et le Feydeau), qui permet à un héros dévoué, et dans la circonstance à une héroïne, incarnation de la beauté et de la paix, par opposition à la noirceur et à la barbarie des bourreaux, de remettre en liberté une victime innocente. C'est aussi et avant tout un manifeste politique des plus explicites. Aucune imitation de Schiller n'est plus tentée, malgré l'ambiguité du titre. Ne demeure de son credo que le constat édulcoré fait par le héros, Villiam : «Le ciel, sa vengeance est bien lente » (acte I, scène 2). Villiam et sa femme Jenny ont choisi de se camoufler aux marges du royaume, dans les zones réputées moins policées des forêts en montagne, que laisse entrevoir le décor du premier acte sur lequel s'ouvre leur chaumine. Ils fuient les persécutions d'un Protecteur qui dispose à sa solde de militaires dévoyés (le colonel Kirk et le lieutenant Bluck) qui s'appliquent à tout détruire sur leur passage, pillant, violant, brûlant, tuant sans considération de l'âge et du sexe, selon des méthodes qui rappellent Turreau ou les noyades de Nantes. Et l'on entend au loin « les cris effrayans et les gémissemens de quelques malheureux » (acte I, scène 2). Aux rêveries d'une aurore universelle, pour laquelle Robespierre était prêt à se sacrifier, Villiam oppose la peur de chaque instant, qui empêche de se projeter dans l'avenir et fait refuser le futur que le pouvoir dessine :

« Le jour il faut craindre les approches de la nuit; la nuit il faut redouter le retour de l'aurore. L'aurore, dont la douce clarté vient consoler tout ce qui respire, n'est plus pour nous que le présage des malheurs, et le réveil de nos bourreaux. O tyrannie, que ton règne est long! Que ton spectre est pesant! Que ton joug est honteux! » (acte I, scène 1).

L'armée de Kirk investit bientôt la retraite du couple, et avec elle la terreur : tandis que la beauté de Jenny en fait immédiatement un objet de conquête, Villiam est jugé sur sa mine. "Sa figure m'est suspecte » prétend Bluck (acte I, scène 9), ce qui n'est pas sans rappeler certaines proclamations des juges des tribunaux d'exception - ainsi Dorfeuille, à la tête de la Commission populaire de Ville-Affranchie, qui avouait : " nous n'avions ni preuves par écrit, ni preuves testimoniales il fallait souvent lire le crime sur le front des coupables $\rangle^{41}$. Les motifs de suspicion s'accu-

(41) Archives parlementaires, tome LXXXII, Paris, 1913, p. 59-60. Séance du $1^{\mathrm{er}}$ nivôse an II (21 décembre 1793). Cf. Philippe Bourdin, « Les tribulations patriotiques d'un missionnaire jacobin, Philippe-Antoine Dorfeuille », Cahiers d'Histoire, tome XLII, Lyon, 1997, n² 2, p. 217-265. 
mulent : le vin servi à table est tenu pour du luxe; le terme d' « honnête homme » dont ses voisins désignent son hôte, qui renvoie à celui d' « honnête gens » dont s'est alors saisi le discours politique, incite Kirk à la méfiance. Enfin, avant que ne soit découvert, suite à une ruse du colonel, le signe politique que Villiam garde sur le cœur (et l'on pense alors au cœur vendéen) (acte I, scène 12), ce dernier refuse de chanter l'hymne des soldats, très évocateur des confusions sémantiques entre brigands, factieux, rebelles, et tout autant des méthodes des persécuteurs, décrits sans beaucoup de fard comme ceux de l'an II (acte I, scènes 5 et 10) :

« Victoire, victoire, victoire!

Les brigands tombent sous nos coups;

Tout tremble, tout fuit devant nous.

Jour de triomphe, jour de gloire,

Répandons partout la terreur,

La mort, le carnage, l'horreur!

Point de pitié, point de clémence!

Quand nous trouvons des factieux.

Envoyons-les en diligence

Aux enfers revoir leurs ayeux

Bien sot est celui qui s'honore

D'épargner ceux qu'il a vaincus!

Les vaincus reviennent encore,

Mais les morts ne reviennent plus.

Pour effacer jusqu'à la trace

Des rebelles et des brigands,

Il faut exterminer leur race

Dans leurs femmes et leurs enfans;

Des cris de nos jeunes vipères

Que nos cœurs ne soient point émus!

Ces enfans vengeroient leurs pères;

Mais les morts ne se vengent plus. »

Villiam est emprisonné, et bientôt condamné à la guillotine, après avoir crânement déclaré : «Je déteste les bourreaux qui parlent de liberté » (acte II, scène 9). Les deux autres actes vont être consacrés, dans les décors lugubres d'une vaste salle nue où Kirk règne en maître, puis dans celui, misérable de la chambre rustique dans laquelle Jenny s'est 
réfugiée, à la tentative de corruption de celle-ci par Kirk, mû par un désir sexuel avoué - où l'on retrouve l'argument de Mesure pour mesure de Shakespeare... Au moment où tout semble devoir basculer, le sauvetage va venir d'un militaire resté pur, le colonel en second Norton, effrayé de la besogne sanglante qu'on lui ordonne (acte 1, scène 5). Se recommandant de la devise "Justice, Clémence, Humanité » (acte II, scène 7), il sait pouvoir compter sur la fidélité de ses hommes, dont il est aimé d'une façon que regrette Kirk : "Nos soldats ne se mêlent pas de politique; ils ne songent qu'à combattre et à vaincre » (acte II, scène 11). Norton fait donc arrêter Kirk et Bluck, leur promettant un vrai procès (que le bourreau " sente enfin le poids de cette justice qu'il a toujours outragée ", acte III, scène 7) et libérer les prisonniers. Au-delà de l'image volontairement naïve de ce que sont devenus les soldats de l'an II, qui n'ont pas tous mis leur mouchoir sur leurs opinions, le vrai sauvetage de l'histoire est bel et bien celui de la République par les forces armées. Le théâtre contribue à en accréditer l'idée avant même que les années du Directoire ne la renforcent.

Mais de ces années-là, où le brigandage connaît des développements multiples mêlant crime et politique, où celle-ci n'hésite pas à user de manière indifférenciée du terme de " brigand » pour désigner alternativement les adversaires de gauche ou de droite, ne date aucune création théâtrale qui vienne nourrir les polémiques; on rejoue le répertoire précédent. Comme si tout avait déjà été dit sur les rapports de l'individu au collectif, sur les formes de l'oppression ou de la résistance politiques, sur celles des tribunaux populaires ou révolutionnaires, dont plusieurs de ces pièces reproduisent des séances, et toutes les formes scéniques adéquates envisagées. Le corpus consacré au brigandage, au total, paraît des plus faibles au regard des quelques centaines de créations patriotiques, des quelques milliers de créations en général. Sans doute l'ombre du héros de Schiller et celle de ses mauvais sosies ont-elles durablement occupé l'espace, ne permettant guère à d'autres d'y mettre pied; on les retrouve furtivement dans d'autres formes littéraires, comme le roman de DucrayDuminil, Victor ou l'Enfant de la forêt (1797), ou l'adaptation mélodramatique éponyme de Pixerécourt l'année suivante, qui font de Victor le fils d'un « chef de brigands ", vingt ans après ${ }^{42} \ldots$ Et, si le voleur de grand chemin a seul encore droit de cité, c'est pour retrouver ces divertissements que Carmontelle n'aurait pas reniés, sans envergure psychologique ni mili-

(42) Pierre Frantz, « Le crime devant le tribunal du théâtre ... », art. cit. 
tante, fût-ce chez un auteur aussi engagé que Picard. Ainsi dans Les Comédiens ambulants, opéra en deux actes écrit par celui-ci et composé par Devienne. Le Théâtre de la rue Feydeau le présente pour la première fois le 28 décembre 1798; il tient ensuite onze mois l'affiche, pour quarantequatre représentations. L'Almanach des Muses pour l'an VIII en fait le résumé suivant (p. 304-305) :

« Des comédiens sont en route pour Beaugency. L'un d'eux rencontre, dans une forêt, un militaire, son cousin, chargé d'une valise que des brigands avaient volée, et qu'il les a forcés d'abandonner. Le militaire veut porter cette valise à Beaugency, et la déposer chez le juge de paix. Mais le comédien s'est soulagé du poids d'une valise dont il était aussi chargé; l'une ressemble parfaitement à l'autre. Le militaire se trompe, et emporte celle de son parent. Bientôt après un villageois, caché dans une masure, est témoin d'une scène de voleurs que les comédiens répètent dans les bois; il les suit à Beaugency et les dénonce. Descente de justice chez eux ; inventaire de leurs effets par le greffier du juge de paix. Ce sont des habits de théâtre, ce sont les dépouilles de ceux qu'ils ont attaqués. Le soupçon devient preuve quand on ouvre la valise contenant des effets que des brigands sont accusés d'avoir volés. Mais l'arrivée du militaire explique tout, et on finit par souper chez le greffier du juge de paix. [...] Beaucoup de naturel et de gaîté. Très jolie musique ».

La chape de silence que le Consulat, puis l'Empire, tentent de faire tomber sur l'art et la littérature révolutionnaires, n'est guère favorable à la pérennité des productions de circonstance de La Martelière, de Briois, d'Hoffman et compagnie, qui rappellent un passé récent et des catégories politiques également recomposés par les nouvelles autorités. La lutte contre le brigandage est plus que jamais affaire d'État, justifiant des tribunaux spéciaux et des pressions insistantes sur les préfets, une redéfinition juridique et pénale des actes incriminés. Dans les pays occupés, les répertoires nationaux sont suspects : à Hambourg, en 1811, «il est d'un intérêt plus pressant qu'on ne le croit d'empêcher que les pièces de Schiller, de Goethe et de quelques autres n'enracinent dans le cœur des générations naissantes une haine profonde contre l'ordre social et contre les autorités légitimes ». Si son succès est sans faille auprès du public allemand (d'autant que la pièce est plus que jamais parée de couleurs nationales), et justement parce que ce succès inquiète, le jugement des autorités d'occupation sur Die Raüber est alors sans appel : «Production absurde, monstrueuse, immorale; les principes erronés de cet ouvrage 
insultent à la fois au bon sens, aux mœurs, à la religion et à tout gouvernement régulier ${ }^{43}$. En France, un autre monde social et esthétique s'ouvre désormais aux figures de brigands, que l'univers balzacien n'oublie pas. Le critique Jules-Gabriel Janin, qui regrette dans Robert, chef des brigands l'absence de la violence du drame romantique, préfèrera le personnage de Robert Macaire, popularisé au Théâtre de la Porte Saint-Martin ou à celui des Folies-Dramatiques au début des années 1830, et croqué par Honoré Daumier. L'autre Robert pose désormais en ancêtre; l'image du brigand s'est éloignée de son idéalisation première, celle de Robin des Bois, celle des complaintes à Mandrin ou à Cartouche : «En ce tempslà Robert Macaire n'était pas inventé. J'aurais voulu voir Baptiste aîné aux prises avec les haillons, avec la graisse et le sang de Robert Macaire. Fortes fortuna adjuvat! La Fortune aime les gens de cœur $»^{44}$.

\author{
Philippe BOURDIN \\ Centre d'Histoire « Espaces \& Cultures » \\ Université Blaise-Pascal \\ Maison des Sciences de l'Homme \\ 4, rue Ledru / 63000 Clermont-Ferrand \\ phbourdin@laposte.net
}

(43) AN F73493. Rapports au duc de Rovigo, 10 février 1811. Le commissaire en charge du contrôle de la salle de théâtre hambourgeoise, ajoute : " L'auteur a cherché à ériger le brigandage en vertu, l'assassinat en justice réglée : une bande d'étudiants échappés d'une université veulent affranchir l'Allemagne, pillent et égorgent tous les princes qu'ils rencontrent sur leur passage, sous prétexte de vexations commises par ces mêmes princes envers leurs sujets. Un prêtre vient offrir le pardon aux brigands; il est bafoué, avili. J'ai assisté à dix représentations de cet ouvrage; les Français qui étaient dans la salle et qui comprenaient l'allemand frémissaient d'indignation. Les Allemands au contraire étaient dans l'enthousiasme, trouvaient les idées de leur poète favori sublimes. Et quelles sont-elles, ces idées sublimes? L'anéantissement de tout ordre social. Des gens dignes de foi m'ont assuré que des étudiants de Leipsick se sont fait brigands de grand chemin, la tête montée et égarée par la lecture ou la représentation de cette horrible production. Cet ouvrage n'a jamais été représenté à Vienne, malgré la sollicitation des gens de la cour. Le Sénat de Hambourg a donné la singulière permission au Directeur du Théâtre de la Ville de jouer cette tragédie-drame quatre fois dans l'an. Lorsqu'on la voit affichée, à quatre heures on ne trouve plus de place ». Je remercie beaucoup Rahul Markovits de m'avoir indiqué ces sources.

(44) Jules-Gabriel Janin, Histoire de la littérature dramatique, Paris, Michel Lévy, 1855, tome 2, p. 239-240. 